KENOSIS : JURNAL KAJIAN TEOLOGI

ISSN 2460-6901(Print), 2656-4483 (Online)

https://e-journal.iaknambon.ac.id/index.php/KNS

DOI: $10.37196 /$ kenosis.v7i2.331

\title{
SPIRITUALITAS MAKAN BERSAMA: Interkoneksi Sesama Ciptaan dalam Praktik Pemeliharaan Alam
}

\section{Christina Dameria dan Dewi Sintha Baratanata}

\author{
Sekolah Tinggi Filsafat Theologi Jakarta \\ Jl. Proklamasi No.27, RT.11/RW.2, Pegangsaan, \\ Kec. Menteng, Kota Jakarta Pusat, DKI Jakarta 10320 \\ cdameria@gmail.com \\ dewisintha@gmail.com
}

\begin{abstract}
Eating together is a culture that was born along with human civilization. Eating together becomes a symbol in both religious and cultural rituals. Christianity notes that eating together becomes a medium in spreading the gospel that Jesus and His disciples did. The symbolic meaning presented in the practice or culture of eating together is acceptance and fellowship. Acceptance is defined as a space to acknowledge the equality of fellow human beings, which creates a sense of solidarity. At the same time, the fellowship provides space to connect. In addition, eating together fulfills the body's physical needs for hunger and restores the freshness of the soul from fatigue. This article tries to connect symbols in eating together to present spirituality in viewing other creations, namely nature that has been damaged. Natural damage needs to be seen as a reality that must be faced and resolved $t$ in the spirituality of eating together. Another creation is nature being the poor, oppressed, marginalized and sick. The solidarity presented in the moment of eating together becomes a new perspective in seeing the context of the destruction of nature and the awareness to build the disconnected interconnection of fellow creations.
\end{abstract}

Keywords: Spirituality, Eating together, Solidarity, Interconnection

\begin{abstract}
Abstrak
Makan bersama merupakan budaya yang lahir seiring dengan peradaban manusia. Makan bersama menjadi simbol baik dalam ritual keagamaan maupun budaya. Kekristenan mencatat bahwa makan bersama menjadi sebuah media dalam mengabarkan Injil yang dilakukan Yesus dan para murid-Nya. Makna simbolik yang dihadirkan dalam ritual atau budaya makan bersama adalah penerimaan dan persekutuan. Penerimaan diartikan sebagai sebuah ruang untuk mengakui adanya
\end{abstract}


persamaan terhadap sesama manusia yang menimbulkan rasa solidaritas. Sedangkan persekutuan memberikan ruang untuk saling terhubung satu dengan yang lain. Selain itu makan bersama tidak sekadar memenuhi kebutuhan fisik tubuh akan rasa lapar tetapi juga mengembalikan kesegaran jiwa akan rasa lelah. Artikel ini mencoba menghubungkan simbol-simbol dalam makan bersama untuk menghadirkan spiritualitas dalam memandang ciptaan lain yaitu alam yang telah rusak. Kerusakan alam perlu dipandang sebagai sebuah kenyataan yang harus dihadapi dan diselesaikan bersama dalam spiritualitas makan bersama. Ciptaan lain yaitu alam menjadi yang miskin, tertindas, tersingkir dan sakit. Solidaritas yang dihadirkan dalam momen makan bersama menjadi sebuah perspektif baru dalam melihat konteks kerusakan alam dan kesadaran untuk membangun interkoneksi sesama ciptaan yang terputus.

Kata kunci: Spiritualitas, Makan bersama, Solidaritas, Interkoneksi

\section{PENDAHULUAN}

Sejarah peradaban bahkan penciptaan makhluk hidup mengungkap bahwa makan adalah bagian yang tidak terpisahkan dari kehidupan itu sendiri. Makan adalah kebutuhan utama dari manusia dan ciptaan lainnya. Dengan makan manusia hidup, dengan mengolah makanan manusia mempengaruhi peradabannya. ${ }^{1}$

Di belahan dunia manapun, dalam beragam konteks dan kultur manusia, makan bukan hanya menjadi sebuah kebutuhan. Makan bersama menjadi wadah perjumpaan dan komunikasi. Perjumpaan yang tidak semata karena apa yang dimakan, melainkan sampai pada yang bersama ikut makan. ${ }^{2}$ Pada saat makan, komunikasi yang tercipta bukan semata pada makanan dan peralatan makan yang digunakan, tetapi lebih dalam lagi pada relasi interpersonal dari yang bersama makan. ${ }^{3}$ Oleh karena itu, kendati pun makan adalah hal yang biasa dan berlaku pada semua makhluk hidup, tetapi makan memiliki kedalaman makna yang tak dapat diabaikan.

Selama ini makan bersama hanya dimaknai sebagai sebuah simbol persekutuan antar sesama manusia. Makan bersama akan memiliki makna yang lebih luas dan dalam jika makan bersama dimaknai sebagai sebuah simbol membangun relasi dan keterkaitan sesama ciptaan. Manusia sebagai imago dei dapat menjadi pihak memprakarsai dalam membangun spiritualitas makan bersama bersama seluruh ciptaan.

Seperti kita ketahui bahwa kerusakan alam semakin luas dan dampaknya dapat kita rasakan bersama. Sebagai salah satu ciptaan yang menerima mandat budaya, 
selayaknya manusia mengambil peran dalam membangun spiritualitas makan bersama dalam lingkup yang lebih luas. Makan bersama tidak sekadar jamuan makan secara lahiriah namun spiritualitas yang kita bangun untuk membangun interkoneksi manusia dan alam dalam kehidupan bersama. Alam yang rusak menyebabkan rusaknya interkoneksi sesama ciptaan dan lebih dalam relasi manusia dengan Allah. Makan sebagai kebutuhan dasar makhluk tidak sekedar dinikmati sebagai pemenuhan kebutuhan dasar, melainkan menjadi media membangun spiritualitas dengan Tuhan, sesama manusia dan ciptaan lain.

Tulisan ini bertujuan untuk memaparkan dan mengonstruksi bentuk spiritualitas makan bersama yang dapat dibangun oleh manusia pada umumnya dan oleh komunitas iman yaitu gereja khususnya dalam memelihara alam. Perspektif makan bersama dapat menjadi basis dalam penyadaran dan menumbuhkan sikap peka terhadap pemeliharaan alam sebagai sesama ciptaan. Konsep makan bersama tidak sekadar ditujukan untuk sesama manusia dalam sebuah komunitas akan tetapi lebih jauh lagi melibatkan sesama ciptaan yang ada di bumi. Spiritualitas makan bersama yang telah dibangun sebagai sebuah budaya manusia dapat menjadi perspektif baru dalam membangun semangat solidaritas terhadap sesama ciptaan. Solidaritas yang menimbulkan semangat pembebasan bagi ciptaan lain yang terpinggirkan, miskin dan tertindas.

\section{METODE PENELITIAN}

Penulisan artikel ini menggunakan studi pustaka (library research). Penelitian dilakukan dengan mengumpulkan, mempelajari, dan menganalisa data-data kepustakaan melalui buku-buku dan jurnal-jurnal. Data-data yang dipelajari dan dianalisa meliputi dua kategori yaitu literatur di bidang sosiologi dan antropologi tentang makan bersama dan bidang teologi. Proses penelitian meliputi penelusuran perkembangan sejarah dan budaya tentang makan bersama baik dalam konteks Kekristenan maupun budaya lokal. Konteks sejarah dan budaya kemudian dianalisa tentang makna dan simbol dari makan bersama dalam konteks Kekeristenan kemudian dianalisa dan disandingkan dengan konteks kerusakan dan pemeliharaan alam. Analisa yang digunakan penulis adalah dengan menggunakan lensa teologi konstruktif. 


\section{HASIL DAN PEMBAHASAN}

\section{Makan Bersama Dalam Konteks Sosial}

Makan dalam hidup sehari-hari memiliki peranan penting bahkan kuat. Selama sejarah peradaban manusia, makan, makanan dan makan bersama menjadi realitas sosial yang dialami dan diturunkan dari generasi ke generasi. Di saat makan orang melakukan interaksi sehingga terjadi kontak sosial. Sebuah keluarga yang berkumpul dan makan bersama-sama menjadikan kesempatan itu untuk berbagi cerita atau peristiwa yang mereka alami khususnya dalam kehidupan sehari-hari. Di semua budaya, makan bersama adalah artikulasi penting dalam komunitas sosial manusia. ${ }^{4}$

Pembahasan tentang makan bersama ditelaah dengan seksama oleh Robertson Smith dengan mendasarkan penelitian pada agama-agama Semitis. ${ }^{5}$ Smith menyatakan bahwa mereka yang duduk bersama untuk makan bersatu untuk semua efek sosial; mereka yang tidak makan bersama adalah orang asing satu sama lain, tanpa persekutuan dalam agama dan tanpa kewajiban sosial timbal balik. Smith memfokuskan pembahasannya pada relasi agama dan makan bersama dalam makna pengorbanan. Ia menyatakan bahwa mereka yang makan dan minum bersama terikat satu sama lain dalam persahabatan dan kewajiban yang sama. ${ }^{6}$

Makan bersama terjadi aksi sosial yang memiliki signifikansi komunikasi. Di sana ada suatu bentuk hierarki dan solidaritas, serta membentuk ikatan yang mengandung makna simbolis. Tentu saja hal-hal ini memiliki implikasi pada hubungan sosial manusia. Makan bersama dalam bahasa Inggris disebut Commensality. Berasal dari dua kata dalam bahasa Latin yaitu com (bersama) dan mensalis (di meja). Jadi Commensalisality bila diartikan secara utuh menjadi makan bersama di satu meja yang sama. Bila merujuk pada kata ini maka tentu makan bersama memberi makna pada sebuah kebersamaan tanpa perbedaan. Orang yang makan bersama di satu meja yang sama berarti memiliki ikatan yang dekat dan karib. Makan di satu meja yang sama tidak hanya menyimbolkan sebuah keramahtamahan namun juga penerimaan satu terhadap yang lain. Karenanya, makan bersama membentuk sebuah ikatan solidaritas bagi yang bersama di meja itu.

Kendatipun makan bersama secara sosial lebih menghubungkan manusia dengan sesamanya, namun dalam dimensi yang lebih luas sesungguhnya setiap orang yang sedang bersama-sama itu terhubung dengan realitas Lingkungan sekitarnya 
termasuk alam. Makan bersama menumbuhkan penghayatan kedalaman relasi antar sesama manusia serta tanggung jawabnya pada kehidupan di sekitarnya sebagai tempat makan bersama. Tempat makan bersama tidak sekadar meja makan dan ruang makan tetapi lingkungan tempat aktivitas makan berlangsung. Dimakani lebih jauh bahwa makanan yang tersedia melibatkan proses melibatkan alam sekitar untuk menyediakan makanan tersebut.

Secara sosial manusia umumnya menggunakan konteks makan bersama sebagai wadah kebersamaan yang mengandung makna sukacita dan rasa syukur. Sukacita dan syukur itu dibalut dalam ungkapan-ungkapan serta doa-doa yang menggambarkan kesadaran manusia secara personal maupun komunitas pada kuasa Sang Khalik yang merahmati manusia juga semua ciptaan dengan kehidupan. Oleh karena itu dalam konteks sosial, makan bersama menjadi perjumpaan dengan manusia dengan Tuhan dan manusia dengan lainnya.

\section{Makan Bersama Dalam Konteks Budaya Jawa dan Minahasa}

Sebagai bagian dari keseharian manusia, makan bersama tentunya telah membentuk kebudayaan manusia. Ada kebiasaan yang kemudian menjadi tradisi dan diteruskan dari satu generasi ke generasi lainnya. Tradisi yang dilanjutkan ini yang membentuk budaya. Pada makan bersama, suatu komunitas memelihara tradisi sebagai bentuk warisan leluhur dan ikatan di antara yang masih hidup.

Dalam kebudayaan Jawa makan bersama dalam jamuan kebersamaan dikenal sebagai Kenduri. Kamus Besar Bahasa Indonesia mengartikan kenduri sebagai perjamuan makan untuk memperingati peristiwa, minta berkat, dan sebagainya. Pada kenduri orang berkumpul dalam sistem kekerabatan masyarakat, menaikkan doa yang dipimpin oleh pemuka adat atau agama lalu dilanjutkan dengan makan bersama. Dalam bukunya Simbolisme Dalam Budaya Jawa, Herusatoto menyatakan kenduri merupakan perwujudan dari nilai-nilai budaya Jawa yaitu budi luhur, lembah manah, dan tepa selira. Pada kenduri orang-orang yang berkumpul memohon doa untuk kelancaran atas sesuatu yang diselenggarakan, serta mengucapkan syukur atas apa yang telah diperoleh. ${ }^{7}$ Kenduri menyatukan segala perbedaan. Rina Dewi Susanti menuliskan bahwa pada kenduri ada sistem nilai yang dibangun, 
Kesatuan sikap dan cita-cita diteguhkan kembali. Bila ada keretakan kecil antara hati dengan hati, maka melalui kenduri persatuan itu dipererat kembali. Kenduri juga merupakan mekanisme sosial untuk merawat keutuhan, dengan cara memulihkan keretakan, kenduri sebagai institusi sosial menampung banyak kepentingan. Semua orang yang mengikuti tradisi ini akan menemukan rasa aman, karena dalam pelaksanaannya tak ada pihak yang kalah atau dikalahkan. Di sana semua pihak terhormat. Tiap orang sama tidak dibeda-bedakan sehingga semua orang yang mengikuti pelaksanaan tradisi ini merasa bahagia. ${ }^{8}$

Hampir seluruh kebudayaan di Indonesia memaknai makan bersama sebagai persatuan. Makan bersama mempersatukan segala perbedaan. Di kebudayaan Bangka Belitung, makan bersama dikenal dengan tradisi Nganggung. Mirip dengan tradisi Kenduri, orang-orang berkumpul menaikkan doa dan melakukan ucapan syukur. Hanya saja tradisi ini dilakukan untuk memperingati hari-hari keagamaan. Hal yang khas pada tradisi Nganggung adalah orang membawa dari rumah masing-masing makanan untuk dinikmati dalam kebersamaan. Pada tradisi Nganggung orang saling berbagi dan bertukar makanan serta menikmatinya dalam suasana keakraban. Makanan yang tidak habis dikumpulkan dalam satu tempat untuk kemudian dibagikan bagi orang lain yang belum sempat makan bersama. ${ }^{9}$

Tradisi makan bersama lainnya dapat ditemukan di Minahasa, Sulawesi Utara. Pada bulan tertentu masyarakat melakukan makan bersama secara massal dan bergiliran dalam skala wilayah. Tradisi ini dikenal sebagai Pengucapan Syukur atau Rumages. Tradisi pengucapan dilakukan sebagai tanda syukur dan sukacita atas panen hasil bumi. Tradisi ini dilakukan secara bergiliran dari satu kampung ke kampung lainnya. Pada tradisi ini, setiap rumah di satu kampung atau wilayah yang mengadakan pengucapan syukur akan mempersiapkan makanan untuk dinikmati oleh setiap orang yang datang bertandang. Biasanya tamu yang datang berasal dari kampung yang lain. Tamu yang datang di kampung tersebut, bebas masuk dan makan di rumah-rumah orang yang dikunjunginya. ${ }^{10}$

Tradisi makan bersama pada kedua budaya di atas memperlihatkan ikatan sosial yang dibangun dalam kesadaran saling membutuhkan satu sama lain. Makan bersama menjadi wadah perjumpaan yang mempersatukan. Setiap orang diterima dalam segala perbedaannya. Setiap orang menjadi guyub dalam ikatan keakraban dan kekerabatan. Nilai-nilai yang terkandung dalam tradisi dilanjutkan ke generasi berikut agar sistem nilai terpelihara dan ikatan sosial serta persaudaraan tidak terputus. 
Dalam kebudayaan-kebudayaan di Indonesia, makan bersama juga sebuah keterlibatan ikatan relasi manusia yang tak dapat abai pada kehidupan di sekitarnya. Pada kebudayaan Jawa, kenduri berangkat dari kesadaran bahwa manusia itu terhubung dengan Sang Ilahi dan ciptaan lainnya. Kenduri menjadi bentuk kesadaran manusia untuk terhubung dengan realitas yang tak terjangkau (transenden) namun terasa dekat (imanen). Oleh karenanya ada ritual-ritual dan simbol-simbol yang menghubungkan manusia dengan Sang Ilahi, manusia dan ciptaan lainnya. Selain itu budaya Jawa memaknai alam menjadi representasi kehadiran Allah, sehingga rasa hormat terhadap alam diperlihatkan melalui makanan yang dipersembahkan. Kenduri menjadi simbol pertanggungjawaban etis manusia yang telah menerima rahmat ilahi melalui kehidupan bersama dengan sesama dan semua ciptaan.

Pengucapan di Sulawesi Utara. Kedua tradisi ini mengonfirmasi keterlibatan manusia dengan alam sekitarnya yang sepatutnya selalu disambut dalam rasa syukur dan terima kasih. Kedua tradisi ini menunjukkan pertanggung jawaban manusia untuk melestarikan alam yang darinya hadir berkat untuk memenuhi kebutuhan hidup manusia. Bahkan tradisi ini pun tidak terlepas dari tradisi lainnya pada saat memulai masa tanam yang umumnya juga menggunakan ritual doa dan makan bersama.

\section{Dimensi Makan Bersama Dalam Tindakan Yesus}

Dalam Kekristenan, makan bersama juga merupakan tradisi. Jejak tradisi ini dapat ditelusuri jauh sampai pada kebudayaan Yahudi. Di dalam Alkitab, tradisi makan bersama diketahui merupakan warisan dari gereja mula-mula yang memiliki kebiasaan berkumpul setiap hari dan saling membagikan makanan di antara mereka (Kis. 4:46). Berbagi makanan merupakan simbol dari persekutuan umat yang saling memedulikan satu sama lain.

Yesus sendiri dalam penuturan Injil-injil Sinoptis juga memberikan gambaran tentang arti duduk makan bersama. Bahkan acap kali Yesus menggunakan momen makan bersama itu sebagai kesempatan membagikan pengajaran-Nya. Misalnya, ketika ia menemui Marta dan Maria di Bethania. Pertemuan dengan kakak beradik ini juga terjadi dalam komunitas makan bersama. Ia menggunakan kesempatan itu untuk menyampaikan ajarannya. Atau ketika Ia makan di rumah Matius pemungut cukai dan orang-orang Yahudi mempertanyakan sikap-Nya yang dianggap berkompromi dengan 
orang berdosa. Yesus menggunakan momen itu juga untuk menyampaikan pandangannya. Ia berkata, "bukan orang sehat yang memerlukan tabib, tetapi orang sakit. Jadi pergilah dan pelajarilah arti firman ini: yang $\mathrm{Ku}$ kehendaki ialah belas kasihan dan bukan persembahan, karena Aku datang bukan untuk memanggil orang benar melainkan orang berdosa." (Mat. 9:12-13). ${ }^{11}$ Bahkan ketika Ia dan muridmurid-Nya dikelilingi ribuan orang, hati-Nya tergerak untuk memberi mereka makan. Penuturan Injil-Injil Sinoptik menggambarkan situasi yang jauh dari keramaian dan tidak ada makanan yang cukup untuk ribuan orang tersebut. Kendati demikian, perintahnya pada para murid menggambarkan betapa dalamnya penerimaan dan kepedulian Yesus kepada sesama. Perintah-Nya kepada para murid, “..kamu harus memberi mereka makan” (Mat. 14:16, Mrk.6:37, Luk.9:13).

Momen makan bersama digunakan oleh Yesus membangun sistem nilai yang mendobrak kebiasaan umum di masa-Nya. Ketika orang-orang di zaman itu menggunakan standar tertentu dalam relasi dengan sesama, Yesus justru "berevolusi" dengan cara-Nya untuk membongkar standar relasi tersebut. Momen kebersamaan dalam makan bersama dengan orang-orang yang terabaikan dan terpinggirkan, memberikan ruang bagi setiap orang tanpa terkecuali untuk diterima. Saat Ia bersama Lewi anak Alfeus makan di rumah pemungut cukai bersama dengan orang-orang yang dianggap berdosa, orang-orang Farisi mempertanyakan sikap-Nya itu. Tapi tanggapan Yesus menegaskan bahwa Ia memilih berada di tengah orang-orang yang ditolak sesamanya, karena itu adalah tujuan kehadiran-Nya (bdk. Mrk. 2:15). Atau ketika Ia sedang makan bersama di rumah Simon si kusta, Ia menunjukkan keberanian-Nya untuk berada di rumah orang yang dikucilkan oleh lingkungannya. Ia tidak merasa canggung berada di sana. Tindakan-Nya memperjelas arti penerimaan Yesus kepada sesama tanpa terkecuali (Mrk. 14:3). Juga saat perempuan yang dianggap berdosa datang dan mengurapi Yesus dengan minyak yang mahal, sedang Yesus makan di rumah seorang Farisi. Ia tidak merasa harus menolak perempuan itu. Sebab bagi-Nya perempuan itu menunjukkan ketulusan. Ia menjawab kegusaran orang-orang Farisi dengan memberikan perumpamaan tentang dua orang yang berhutang. Ia mengakhiri perumpamaan itu dengan pernyataan jelas dan penuh kasih pada si perempuan, "dosamu telah diampuni. ...Imanmu telah menyelamatkan engkau, pergilah dengan selamat” (Luk. 7:36-50). Keberanian Yesus mendobrak cara pandang dan sistem nilai 
yang telah berakar di antara orang-orang sejaman-Nya, menunjukkan revolusi Yesus dalam spiritualitas yang mengubahkan.

Warisan momen makan bersama yang paling fenomenal adalah perjamuan malam Paskah yang Yesus lakukan bersama murid-murid-Nya. Fenomenal karena pertama, dilakukan dalam perayaan hari Paskah. Semua orang Yahudi menjalani perayaan itu dengan rasa syukur atas tuntunan Allah yang menyelamatkan bangsa Israel keluar dari Mesir. Kedua, momen makan bersama itu sarat makna dengan tindakan simbolis Yesus saat membagikan roti dan anggur di antara mereka. Ia menyimbolkan roti dan anggur sebagai wujud tubuh dan darah-Nya. Ia berkata, “..inilah tubuh- $\mathrm{Ku}$, ...inilah darah-Ku..” saat Tindakan simbolis Yesus itu menjadi amanat untuk diteruskan dari generasi ke generasi berikutnya dari pengikut Yesus. Ketiga, perjamuan makan bersama Paskah itu dilakukan dalam suasana sentimental, akrab dan karib untuk dikenang sebagai "hari perpisahan".

Kekuatan makna makan bersama yang digunakan Yesus, pada dimensi yang lebih luas bahkan menggambarkan kesediaan Allah Tritunggal yang merengkuh segala ciptaan ke dalam kasih-Nya yang menyelamatkan. Saat Yesus membagibagikan roti dan anggur di antara murid-murid-Nya, Ia menyematkan kalimat perintah penting yang penuh makna “... perbuatlah ini menjadi peringatan akan Aku.." (Luk.22:19). Makna peringatan merujuk pada momen yang selalu harus diingat oleh para murid setiap kali membagi-bagikan roti dan anggur dalam perjamuan kudus. Yesus menggambarkan roti dan anggur sebagai peringatan akan tubuh dan darah-Nya yang menjadi tanda keselamatan. Keselamatan itu tentu tidak semata hanya pada manusia akan tetapi dengan alam dan seluruh ciptaan. Allah yang berinkarnasi dalam Yesus adalah Allah yang datang menyelamatkan manusia dan seluruh ciptaan sehingga tidak berada dalam rengutan kuasa dosa yang berakibat maut. Keselamatan itu membawa pemulihan dan pembaruan bagi kehidupan. Konsep keselamatan yang Yesus tawarkan tidak terbatas hanya kepada manusia tetapi juga seluruh ciptaan.

Gambaran tentang makan bersama yang diperlihatkan dalam kisah perjalanan dan pengajaran Yesus ini memberi penanda penting tentang bagaimana Yesus membangun spiritualitas dengan sesama dan bahkan semua ciptaan. Yesus menggunakan momen makan bersama sebagai kesempatan bersosialisasi, 
berkomunikasi, mengajar dan membangun jaringan. Cara Yesus ini efektif untuk membuat orang merasa diterima dan dihisap masuk dalam relasi sesama manusia.

\section{Dialektika Levinas dan Derrida tentang Penerimaan dengan Sesama dan Seluruh Ciptaan}

Tindakan Yesus yang menunjukkan penerimaan tanpa batas pada sesama, menunjukkan kepedulian-Nya yang mendalam kepada sesama. Ia menciptakan relasi sosial yang mendobrak kebiasaan dan pandangan umum. Ia menginspirasi banyak orang untuk terbuka dan peduli kepada yang lain.

Emmanuel Levinas seorang filsuf kontemporer asal Prancis, menggambarkan soal kepedulian terhadap sesama adalah bagian dari tanggung jawab yang total dari manusia. Dalam karyanya Totaly and Infinity, Levinas menyatakan bahwa "yang tak berhingga" itu adalah sesama manusia yang tadinya berperan sebagai orang asing bagi individu yang lain. Dalam hal inilah, totalitas individu menjadi hancur karena setiap individu harus berhubungan dengan sesamanya manusia. Setiap manusia memiliki kewajiban etis terhadap sesamanya. Kewajiban itu bersifat asimetris karena relasi antar manusia itu semestinya dibangun dalam kesadaran saling memberi tanpa pamrih. Apa yang telah diberikan kepada orang lain tidak boleh diminta balasannya. Subjektivitas manusia itu dibangun dalam heteromoni, dalam tanggung jawab yang tak terbatas (infine responsibility) dengan sesamanya. Levinas menyatakan bahwa etika kasih dalam diri manusia diwujudkan bukan dengan keberadaan diri kita sendiri di dunia ini tetapi cara kita menerima keberadaan orang lain atau sesama dalam kehidupan kita bersama. ${ }^{12}$

Levinas menggunakan fenomenologi wajah dalam interpretasi tentang sesama manusia (the other). Pada sesama ada wajah yang sedang berhadapan langsung dengan diri kita dan menuntut sebuah pertanggungjawaban etis. Wajah yang memandang kita adalah "yang lain" (the other) yang sedang memperlihatkan dirinya melampaui ambisi manusia untuk menguasai sesamanya. Bagi Levinas kewajiban manusia kepada sesamanya (the other), sepatutnya dalam kesadaran untuk “menyambut yang lain.” Penyambutan yang seperti itu merupakan respons mengenali sesamanya dari apa yang dibutuhkan oleh sesamanya itu. Itu merupakan berkat dalam relasi manusia. Dalam karyanya Otherwise than Being or Beyond Essence Levinas 
mengembangkan konsep "tanggung jawab tak terbatas" dan berpendapat bahwa manusia sepatunya bertanggung jawab kepada sesamanya bahkan sebelum adanya kesadaran atau tindakan apa pun. Ia menuliskan,

"Responsibility for the Other is not an accident that happens to a subject, but precedes essence in it, has not awaited freedom, in which a commitment to another would have been made. I have not done anything and I have always been under accusation - persecuted. The ipseity, in the passivity without arche characteristic of identity, is hostage. The word I means here I am, answering for everything and for everyone." 13

Lebih lanjut Levinas menyatakan tentang tanggung jawab tak terbatas manusia pada sesamanya, yaitu :

Vulnerability is obsession by others or approach to others. It is for others, from behind the other of the stimulus. An approach reduced neither to representation of others nor to consciousness of proximity. To suffer by the other is to take care of him, bear him, be in his place, consume oneself by him. All our love or hatred of one's fellow man as a thoughtful attitude supposes this prior vulnerability this "moaning of the entrails" mercy. From the moment of sensibility, the subject is for the other: substitution, responsibility, expiation. But a responsibility that I did not assume at any moment, in any present. Nothing is more passive than this challenge prior to my freedom, this preoriginal challenge, this sincerity. ${ }^{14}$

Dasar pemikiran Levinas ini berangkat dari ajaran Taurat Yahudi yang diterima dan dipelajarinya. Menurut Levinas Taurat menyajikan banyak bukti tentang relasi manusia dengan sesamanya, juga karakter-karakter yang tertera di dalamnya. Nilai-nilai etis yang ditawarkan oleh Levinas berangkat dari pengetahuannya tentang Taurat, yang juga merupakan akar dari etika Kristen. Sedikit banyak pandangan Levinas ini memiliki korelasi dengan ajaran Yesus. Menerima setiap orang tanpa batas. Yesus juga mengajarkan tentang tanggung jawab manusia terhadap sesamanya. Dalam Khotbah di Bukit Yesus memberi penekanan tentang bagaimana seseorang harus bersikap terhadap sesamanya.

Pendangan Levinas tentang fenomenologi wajah "yang lain" (the other) yang telah dipaparkan sebelumnya, dapat ditafsirkan juga sebagai gambaran melihat wajah alam dan ciptaan lainnya sebagai wajah sang transenden yang menampakkan diri pada manusia. Berdasarkan fenomenologi wajah maka alam dan ciptaan lainnya yang hadir dalam kehidupan dapat disikapi dengan dua cara. Pertama, wajah alam dan ciptaan lainnya menggambarkan sebuah ketidakberdayaan yang menghimbau tindakan etis. 
Alam dan ciptaan lainnya adalah wajah "yang lain" (the other) yang menampakkan diri pada manusia. Wajah alam dan ciptaan lainnya sangat berbeda dari manusia, akan tetapi hadir dalam bentuknya yang khas dan tak terpisah dari kehidupan. Konsekuensinya adalah wajah alam dan ciptaan lainnya itu diterima tanpa berusaha menguasai, mengeksploitasi atau pun menghancurkannya. Kedua, alam dan ciptaan lainnya adalah wajah yang sedang berhadapan dan menatap langsung pada manusia. Wajah yang menatap itu menuntut sikap yang bukan semata tentang moral, melainkan pertanggungjawaban. Pertanggungjawaban etis teologis untuk menerima alam dan ciptaan lainnya sebagai bagian dari kehidupan di mana manusia pun merasakan rahmat Sang Ilahi di dalamnya.

Sementara itu Derrida seorang filsuf kontemporer Perancis yang dianggap sebagai pengusung tema dekonstruksi di dalam filsafat pasca modern berpendapat etika adalah keramahan dan keramahtamahan adalah etika. Menerima sesama dalam kehidupan adalah bagian dari keramahtamahan (hospitality) manusia. Ini adalah perwujudan filosofi yang terbuka, yang selalu membuka diri pada Yang Lain (The Other), Mesias asing, sang mustahil. Derrida sendiri membuat klaim ini, menulis:

If every concept shelters or lets itself be haunted by another concept, by an other than itself that is no longer even its other, then no concept remains in place any longer. This is about the concept of concept ... hospitality, the experience, the apprehension, the exercise of impossible hospitality, of hospitality as the possibility of impossibility (to receive another guest whom I am incapable of welcoming, to become capable of that which I am incapable of) - this is the exemplary experience of deconstruction itself, when it is or does what it has to do or to be, that is, the experience of the impossible. Hospitality - this is a name or an example of deconstruction. ${ }^{15}$

Cara pandang Derrida tentang keramahtamahan terhadap orang lain memang unik, tak biasa. Menurutnya orang lain atau orang asing adalah bukti nyata hukum heteronomi. Oleh karena itu mempersembahkan keramahtamahan bukanlah sebuah tindakan yang otonom, bukan juga kebebasan yang absolut, tetapi itu memang respons kita terhadap orang lainnya yang sejak awal sudah ada pada diri kita. Heteronomi dan perubahan, bukanlah kebebasan yang otonom, melainkan dasar eksistensi manusia. Berikutnya. Derrida menggunakan "keramahtamahan" neologisme untuk menyatakan bahwa ada potensi kekerasan dalam sikap keramahtamahan. Derrida mengindikasikan 
hubungan antara "permusuhan" dan "keramahtamahan." Pandangan Derrida tentang hal ini dirangkum sebagai berikut:

The hospes is someone who has the power to host someone, so that neither the alterity (hostis) of the stranger nor the power (potentia) of the host is annulled by the hospitality. There is an essential "self-limitation" built right into the idea of hospitality, which preserves the distance between one's own and the stranger, between owning one's own property and inviting the other into one's home. So, there is always a little hostility in all hosting and hospitality, constituting a certain "hostil/pitality. ${ }^{16}$

Derrida melakukan analisa dekonstruktif dengan mendengarkan suara-suara dari kalangan menengah, memberikan perhatian pada konstruksi keramahtamahan tentang siapa "tuan rumah" dan "tamu"nya, siapa yang "disandera" dan yang jadi "musuh", "orang asing" dan siapa sang "dermawan". Analisa terhadap peran-peran tersebut meninggalkan pertanyaan, apakah keramahtamahan terjadi karena undangan tuan rumah, atau karena tamu yang bertandang ke rumah? Atau apakah keramahtamahan itu bergantung pada hubungan timbal balik antara tuan rumah dan tamunya? Apakah model yang seperti itu memang dapat bertahan? Atau, apakah itu terjadi karena kedermawanan? Apakah masih penting atau menarik membangun ikatan dan batasan dari keramahtamahan? Ataukah keramahtamahan itu membutuhkan penerimaan dari semua orang?

Bagi Derrida, konsep keramahtamahan yang logis dibangun oleh antinomi dan aporia yang absolut. Di satu sisi, ada hukum keramahtamahan yang tak terbatas yang memungkinkan orang menerima orang asing tanpa syarat. Tapi di sisi lain, ada batasan hukum keramahtamahan terhadap orang lain yang memang mengharuskan sejumlah persyaratan misalnya pada soal politik, yuridis dan moral. Bagi Derrida, sikap dan keputusan yang bertanggung jawab perlu secara terus menerus dinegosiasikan di antara persyaratan-persyaratan yang beragam ini.

Menarik ketika Derrida melakukan analisa dekonstruktif keramahtamahan manusia ini, ia tidak sedang semata-mata berpusat pada diri manusia dan kepentingankepentingannya semata. Justru ia sedang menggugah kesadaran manusia untuk menemukan kebenaran-kebenaran yang tidak hanya berpusat pada satu sisi, melainkan pada sisi yang lain juga. Bahwa setiap wujud kerahamtamahan membutuhkan kesanggupan manusia bertanggungjawab atasnya. 
Konsep keramahtamahan Derrida ini juga memberi ruang refleksi tentang pertanggungjawaban manusia terhadap alam dan ciptaan lainnya. Konsep keramahtamahan Derrida menjadi ruang telisik atas penerimaan manusia terhadap kehidupannya bersama dengan alam dan ciptaan lainnya. Pada keramahtamahan terkandung makna ketulusan, kebaikan, kematangan emosi dan relasionalitas yang dewasa serta bertanggung jawab. Keramahtamahan menjadi oposisi biner yang menegaskan bahwa segala bentuk kebencian, kemarahan, kekerasan, kerusakan dan kehancuran. Keramahtamahan menuntun manusia memandang alam dan ciptaan lainnya sebagai ruang kehidupan yang wajib diterima dengan penuh ketulusan dan kebaikan, serta mengabaikan egosentrisme yang berpusat pada pementingan diri sendiri.

Meskipun kedua pemikiran Levinas dan Derrida bertolak belakang akan tetapi keduanya dapat diambil makna bahwa keramahtamahan memiliki tanggung jawab. Tanggung jawab yang dapat diaplikasikan di luar meja makan, yaitu dalam kehidupan bersama untuk saling memberikan kehidupan. Manusia diajak untuk membuka sekat egonsentris dan mulai memandang kehidupan di luar dirinya sendiri sebagai pusat hidupnya.

\section{Spiritualitas Makan Bersama Membangun Interkoneksi dan Wujud Solidaritas Sesama Ciptaan}

Meja makan merupakan simbol yang dihadirkan Yesus untuk menerima semua manusia tanpa sekat atau batasan. Tindakan makan bersama menjadi simbol penerimaan orang-orang yang terbuang, tertindas, miskin dan teraniaya. Makan bersama juga memberi makna bahwa memberi energi baru bagi fisik yang berimbas kepada jiwa. Hal ini tampak ketika Yesus menampakkan diri kepada dua orang murid di jalan menuju Emaus (Lukas 24:30). Demikian juga dalam peristiwa Yesus memberi makan lima ribu orang (Yoh 6:1-15).

Yesus memberi teladan bahwa makan bersama menjadi media dalam membuka ruang penerimaan bagi sesama dan ciptaan lainnya tanpa sekat. Makan bersama sebagai sebuah momentum bagi sesama ciptaan untuk saling terhubung. Dengan demikian sesama ciptaan tidak sekadar berada pada satu tempat yang sama tetapi sesama ciptaan juga terhubung satu dengan yang lain. Kesadaran manusia 
bahwa dirinya bukan satu-satunya mahkluk di bumi ini memberikan kesempatan dan ruang untuk mengubah cara pandang bahwa spiritualitas makan bersama adalah perjumpaan manusia dan ciptaan lainnya.

Konteks makan bersama dapat menjadi dasar pemikiran yang membangun interkoneksi tidak terbatas manusia dengan manusia tetapi manusia dengan sesama ciptaan. Konsep interkoneksi antar ciptaan dapat mengambil salah satu pemikiran Paus Fransisku melalui ensiklik Laudato Si pada tahun 2015. Laodato Si menjadi sebagai sebuah seruan yang mengajak manusia menyadari bahwa bumi adalah rumah bersama. Jika ditilik Kembali, Laudato Si menjadi sebuah pengembangan pemikiran Fransiskus Asisi akan sikap yang ditunjukkan kepada sesama ciptaan. Interkoneksi dimulai dengan keterbukaan terhadap sesama ciptaan melalui pemberian makna bahwa setiap makhluk hidup diciptakan sama keberadaannya dengan fungsi yang saling melengkapi. Fransiskus Asisi menyadari bahwa Allah sebagai pencipta dan alam sebagai ciptaan-Nya memiliki keterkaitan. Sikap hormat kepada Allah dapat kita tunjukan melalui sikap hormat dengan menghargai sesama ciptaan termasuk alam. Fransiskus Asisi menyebutkan alam sebagai saudari dan saudaranya. Burung-burung bernyanyi menaikkan pujian bagi Allah. ${ }^{17}$

Dialektika pemikiran Derrida dan Levinas tentang makan bersama sebagai simbol penerimaan dan keramahtamahan dapat dikaitkan dengan konteks interkoneksi dalam Laodato Si. Interkoneksi dalam Laodato Si mengembangkan pemikiran tentang relasi manusia tidak terbatas dengan Allah dan sesama manusia, tetapi juga manusia dengan alam.

Dokumen ensiklik Laodato Si berisikan seruan untuk mengingat kembali interkoneksi manusia dengan sesama ciptaan di dalamnya alam termasuk tumbuhan dan hewan. Kesadaran bahwa manusia tidak sendiri dan bahwa ciptaan lain memiliki nilai yang sama, maka kesadaran untuk menciptakan keharmonisan melalui integral ekologi tumbuh dan dikembangkan melalui Laodato Si. Ensiklik ini hendak membangun kehidupan spiritualitas yang menjadikan bumi sebagai rumah bersama. Bumi tidak saja untuk manusia tetapi juga tempat tinggal ciptaan yang lain. Ensiklik ini menyatakan bahwa semua ciptaan terhubungan. Gambaran ini selaras dengan spiritualitas makan bersama yang telah di bahas di bagian atas. 
Laudato Si membangun kehidupan spiritual manusia dalam sebuah kesadaran bahwa segala ciptaan memiliki interkoneksi. Alam bukan sebuah obyek sebatas sumber kekayaan yang didomestifikasi. Alam merupakan sebuah subyek yang memiliki nilai religius sebagai wujud pernyataan Allah. Allah yang hadir dalam bentuk alam semesta menghadirkan perspektif bahwa seluruh ciptaan memiliki interkoneksi atau interkoneksi karena di dalam Allah. Kehadiran Allah di dalam semua ciptaan menandakan karakter Allah yang tidak terbatas. Interkoneksi antar ciptaan menjadi sebuah pernyataan bahwa setiap ciptaan memiliki tujuan yang berbeda dan mempresentasikan kasih Allah yang tidak terbatas. Setiap ciptaan memiliki ciptaan memiliki nilai yang sama dengan fungsi yang berbeda. Kepelbagaian fungsi ciptaan menciptakan interkoneksi yang perlu dipelihara. Rusaknya interkoneksi mengakibatkan rusaknya keharmonisan antar ciptaan. Interkoneksiftas sesama ciptaan terpelihara atas dasar saling menghargai satu dengan yang lain. Interkoneksi juga melibatkan relasi ciptaan dan penciptanya. Domestifikasi manusia terhadap alam telah merusak interkoneksi baik manusia dengan alam maupun manusia dengan Allah. Makan bersama menjadi sebuah peristiwa yang memiliki makna dalam peradaban manusia. Simbol yang dihadirkan dalam budaya makan bersama tidak sekadar memenuhi kebutuhan fisik tubuh akan rasa lapar tetapi juga mengembalikan kesegaran jiwa akan rasa Lelah. Selain itu makan bersama menjadi perjumpaan sosial sesama manusia.

Makan bersama adalah sebuah model perjumpaan sosial dalam semangat saling menerima satu sama lain. Dalam makan bersama komunikasi dan relasi terbangun yang dimulai dengan sikap penerimaan. Makanan yang disantap menjadi media untuk mempersatukan semua pihak. Sikap penerimaan yang lain dibangun dengan sikap ramah tamah. Levinas dan Derrida mengungkapkan etika dalam hubungan sosial manusia. Keduanya menawarkan keramahtamahan sebagai etika hidup sesama manusia. Yesus sendiri memperlihatkan keramahtamahan-Nya menerima sesama dalam momen makan bersama. Namun, duduk makan bersama dapat melampaui keramahtamahan itu sendiri. Yesus mengajarkan nilai-nilai tersebut dan menjadi teladan yang patut diikuti. Yesus memberi teladan sikap menerima tanpa syarat untuk diteruskan oleh para pengikutnya. Duduk makan bersama menjadi media berdialog untuk saling menerima tanpa syarat di antara segala perbedaan. Memang 
ada kemungkinan masih ada orang yang belum atau tidak tergabung dalam duduk makan bersama itu. Tapi, teladan Yesus mengingatkan bahwa keramahtamahan seorang Kristen adalah dengan membiarkan meja atau ruang makan bersama itu tidak pernah tertutup. Di ruang atau tempat makan itu, bukan hanya makanan dan minuman jasmani yang disajikan. Tetapi roh, spirit persaudaraan, persahabatan dan penerimaan tanpa batas dan syarat bagi sang liyan di dunia ini.

Letty M. Russel memaparkan bahwa meja makan merupakan tempat setiap orang dapat membawa talenta masing-masing untuk bersama-sama berkomitmen dalam memperjuangkan sesuatu. ${ }^{18}$ Russel lebih jauh menyatakan bahwa di meja makan setiap orang yang makan menikmati makanan yang sama, sehingga tidak ada lagi sekat-sekat perbedaan. Gambaran ini memberikan sebuah perspektif bahwa makan bersama menjadi sebuah momentum untuk ciptaan yang satu dapat menerima ciptaan yang lain. Penerimaan ini juga menandai adanya rekonsiliasi bahwa tidak ada lagi ciptaan yang dipandang lebih rendah atau lebih tinggi dari yang lain. Makan bersama menjadi media untuk saling terhubung dan memberikan kesempatan untuk berelasi.

Penerima dan keramahtamahan menjadi unsur penting dalam spiritualitas makan bersama yang pada akhirnya menghadirkan solidaritas diwujudkan dalam tindakan duduk bersama, penerimaan, dan keramahtamahan. Solidaritas hadir di meja makan dan melalui hidangan yang sama yang dinikmati bersama.

Solidaritas terhadap sesama ciptaan diawali dengan pengakuan bahwa manusia hidup bergantung kepada ciptaan lain. Kehidupan manusia bergantung kepada alam, bukan alam yang bergantung kepada manusia. ${ }^{19}$ Alam sebagai anugerah Allah kepada manusia memberikan nilai bahwa alam bukan sebuah objek tetapi subyek yang hidup bersama-sama dengan manusia. Ketika manusia memandang alam sebagai subyek, maka manusia akan memiliki pemahaman bahwa alam bukan untuk didomestifikasi. Sebagai sesama ciptaan, manusia memiliki tanggung jawab untuk memelihara alam. ${ }^{20}$

Spiritualitas makan bersama dalam interkoneksi manusia dengan alam sebagai sesama ciptaan. Sejalan dengan integral ekologi bahwa ketergantungan manusia sebagai makhluk sosial tidak dapat dipisahkan dengan ciptaan yang lain. ${ }^{21}$ Sikap solidaritas terhadap sesama ciptaan menjadi manusia yang mewujudnyatakan kasih Allah. Solidaritas manusia dengan manusia dan manusia dengan alam. Solidaritas 
menjadi cara manusia dalam mengangungkan kasih Allah. Allah yang agung dan mulia menciptakan alam semesta dengan memberikan karakter keagungan dan kemuliaan pada setiap ciptaan-Nya. ${ }^{22}$ Spiritualitas makan bersama dimaknai sebagai persekutuan universal dengan sesama ciptaan. Persekutuan universal yang dimulai dengan kesadaran mengasihi sesama ciptaan dan manusia bagian dari ciptaan.

Solidaritas menjadi pintu masuk semangat pembebasan bagi ciptaan yang tertindas, tersingkir atau terpinggirkan. Alam yang rusak menjadi 'si miskin' yang tidak mempunyai nilai atas dirinya sendiri karena tidak dapat berfungsi sebagai ciptaan yang utuh. Alam yang rusak menjadi 'si tertindas atau tersingkir' karena alam tidak dapat lagi berguna bagi dirinya sendiri maupun bagi ciptaan lainnya.

Mendefinisikan ulang yang dimaksud dengan subyek tertindas, tersingkir, miskin, sakit merupakan alam yang rusak akan mengantarkan sebuah perspektif baru untuk membebaskan alam yang telah rusak. Alam sebagai subyek yang tertindas, tersingkir, yang miskin, dan yang sakit menjadi sebuah usaha untuk menghubungkan kembali interkoneksi manusia dan alam.

\section{KESIMPULAN}

Spiritualitas makan bersama yang telah diteladani oleh Yesus menjadi pemaknaan manusia menjalin relasi bersama ciptaan lain. Meja makan menjadi sebuah simbol persekutuan antar ciptaan dan tempat untuk membangun interkoneksi yang telah rusak akibat domestifikasi manusia terhadap alam. Manusia dapat menghayati hubungannya dengan alam ketika manusia memiliki perspektif baru bahwa alam adalah anugerah dan pernyataan kehadiran Allah kepada manusia. Dengan demikian manusia tidak memandang alam sebagai obyek tetapi sebagai subyek. Ketika alam sebagai subyek, maka nilai alam akan utuh sebagai sesama ciptaan dan kesadaran untuk duduk makan bersama menjadi wujud terbangunnya solidaritas. Solidaritas yang terbangun menjadikan manusia. Interkoneksi manusia dan alam yang telah rusak dapat diperbaiki dengan memperbaiki relasi manusia dan Allah. Ketika manusia memiliki relasi yang erat dengan Allah sebagai pencipta, kesadaran bahwa manusia bukan pusat ciptaan maka manusia akan membangun kembali relasi yang telah rusak dengan ciptaan lain. ${ }^{23}$ Pemaknaan ulang tumbuhan, hewan, dan alam sebagai saudara/saudari membuka ruang solidaritas. Solidaritas yang ditumbuhkan 
menjadi pintu masuk untuk gerakan pembebasan bagi alam yang tertindas karena domestifikasi manusia. Ketika duduk makan bersama maka kedudukan setiap ciptaan di meja makan adalah sama. Kebersamaan rasa dan kedudukan akan membuka ruang persekutuan dengan semangat sepenanggungan. Semangat sepenanggungan ini muncul melalui topik pembicaraan yang sama di meja makan.

Interpretasi alam sebagai sesama ciptaan yang memiliki nilai yang sama dihadapi Allah menjadi sebuah refleksi ekologi yang berimplikasi pada sikap memelihara alam. Allah yang transeden hadir melalui ciptaan-Nya menjadi Allah yang imanen melalui ciptaan. Perjumpaan sesama ciptaan dalam spiritualitas makan bersama menandai interkoneksi Allah dengan ciptaan dan ciptaan dengan ciptaan. Spiritualitas makan bersama memberi ruang bagi

Menghadirkan spiritualitas makan bersama dalam merespons kerusakan alam memerlukan definisi ulang siapa sesama ciptaan yang duduk makan bersama. Mendefinisikan ulang bahwa alam bukan obyek yang diciptakan untuk sekadar dimanfaatkan akan tetapi subyek yang memiliki nilai sama dengan manusia sebagai ciptaan. Pemaknaan ulang ini berimplikasi pada tumbuhnya perubahan kehidupan spiritualitas bahwa manusia dan alam memiliki interkoneksi satu dengan yang lain.

\section{Endnotes:}

\footnotetext{
${ }^{1}$ Claude Fisher, "Food, Self and Identity," Social Science Information 2, no. 27 (1988): 275-92, https://doi.org/10.1177/053901888027002005.

${ }^{2}$ Kerner Susanne, Chou Cynthia, and Morten Warmind, Commensality: From Everyday Food to Feast (London: Bloomsbury Academic, 2015)

${ }^{3}$ Peter Farb and George Armelagos, Consuming Passions: The Anthropology of Eating (Houghton Mifflin, http://gen.lib.rus.ec/book/index.php?md5=5E098720CA11CD8E2A5BAD40DAF36B63.

${ }^{4}$ Calude Fischer, "Commensality, Society and Culture," Social Science Information 50, no. 3-4 (2011): 528-48, https://doi.org/10.1177/0539018411413963.

5 William Robertson Smith, Lectures On the Religion of the Semites, 1st ed. (London: Adan and Charles Black, 1894).

${ }^{6}$ William Robertson Smith, Lectures On the Religions of The Semites: Journal for Study of The Old Testament Suplement (London: Adam and Charles Black, 1995), http://gen.lib.rus.ec/book/index.php?md5=D1A5C491154EBAECAB635096FF16FE9C.

${ }^{7}$ Budiono Herusatoto, TitSimbolisme Dalam Budaya Jawale, 3rd ed. (Yogyakarta: Hanindita, 2000).

${ }^{8}$ Rina Dewi, “Tradisi Kenduri Dalam Masyarakat Jawa Pada Perayaan Hari Raya Galungan Di Desa Purwosari Kecamatan Tegaldlimo Kabupaten Banyuwangi (Kajian Teologi Hindu),” Jurnal Penelitian
} 
Agama Hindu 1, no. 2 (2017): 489-94, https://docplayer.info/64337671-Dalam-masyarakat-jawa-padaperayaan-hari-raya-galungan-di-desa-purwosari-kecamatan-tegaldlimo-kabupaten-banyuwangi.html.

9 Muhamad Edy Waluyo, "Nilai-Nilai Dan Makna Simbolik Tradisi Nanggung Di Desa Petaling Propinsi Kepulauan Banga Belitung," Sabda: Jurnal Kajian Budaya 10, no. 1 (2017): 1-15, https://doi.org/10.14710/sabda.10.1.1-15.

10 Grace D Kandou, Kebiasaan Makan Makanan Etnik Minhasa Provinsi Sulawesi (Manado: Pemerintah Provinsi Sulawesi, 2009).

${ }_{11}$ Spinks Bryan D, Do This in Remembrance of Me: The Eucharist from the Early Church to the Present Day (London: SCM Press, 2013).

${ }^{12}$ Andrew Shepherd, The Gift of the Other: Levinas, Derrida, and Theology of Hospitality (Cambridge: James Clarke \& Co, 2014).

${ }^{13}$ Shepherd.

14 Shepherd.

15 Shepherd.

16 Shepherd.

${ }^{17}$ Karel Phil Erari, Spirit Ekologi Integral (Jakarta: BPK Gunung Mulia, 2017).

${ }^{18}$ Letty M. Russel, Inheriting Our Mothers' Gardens: Feminist Theology in Third World Perspective (Lousville: The Westminster Press, 1988).

${ }^{19}$ Vincent J Miller, The Theological and Ecological Vision of Laudato Si: Everything Is Connected, ed. J. Miller Vincent (Chennai: Bloomsbury, 2017).

${ }^{20}$ Willis Jenkins, Ecologies of Grace: Environment Ethics and Christian Theology (New York: Oxford University Press, 2008).

${ }^{21} \mathrm{~J}$ Miller, The Theological and Ecological Vision of Laudato Si: Everything Is Connected.

$22 \mathrm{~J}$ Miller.

${ }^{23} \mathrm{~J}$ Miller.

\section{DAFTAR PUSATAKA}

Farb, Peter, and George Armelagos. 1980. Consuming Passions: The Anthropology of Eating. Houghton Mifflin.

Fischler, C. 1988. "Food, Self and Identity.” Social Science Information 27 (2): 27592. https://doi.org/10.1177/053901888027002005.

Fischler, Claude. 2011. "Commensality, Society and Culture." Social Science Information 50 (3-4): 528-48. https://doi.org/10.1177/0539018411413963.

Herusatoto, Budiono. 2000. Simbolisme Dalam Budaya Jawa. Cet. 3. Yogyakarta: Hanindita.

Jenkins, Willis. 2008. Ecologies of Grace: Environmental Ethics and Christian Theology. New Yorks: Oxford UNiverosty Press, Kandou, Grace D. 2009. “Kebiasaan Makan Makanan Etnik Minahasa Provinsi Sulawesi Utara,” 2, 3. 
Kerner, Susanne, Cynthia Chou, and Morten Warmind. 2015. Commensality: From Everyday Food to Feast. Bloomsbury Academic. http://gen.lib.rus.ec/book/index.php?md5=95a2baabef329781cea34c61fd5fc9db.

Miller, J Vincent. 2017. The Theological and Ecological Vision of Laodato Si: Everything is Connected. Chennai: Bloomsbury T \& T Clark, 11Shepherd, Andrew. 2014. The Gift of the Other: Levinas, Derrida, and a Theology of Hospitality.

Phil, Erari Karel. 2017. Spirit Ekologi Integral: Sekita Ancaman Perubahan Iklim Global dan Respons Perspektif Budaya Melanesia. Jakarta: PBK Gunung Mulia, 122.

Russel, M. Letty, at.all. 1998. Inheriting Our Mothers' Garden: Feminist Theology in Third World Perspective. Lousville: The Westminster Press, 153

Sinta. n.d. "Sejarah Pengucapan Syukur Di Minahasa - Penelusuran Google." Accessed December 11, 2018. sinta.ukdw.ac.id/sinta/resources/sintasrv/getintro/01120040/.../intro.pdf.

Smith, William Robertson. 1894. Lectures On the Religion of the Semites, First Series, The Fundamental Institution. 1st. London: Adam and Charles Black.

-1995. Lectures on the Religion of the Semites.: Second and Third Series ((Journal for the Study of the Old Testament Supplement Ser.; Vol. 183)).

http://gen.lib.rus.ec/book/index.php?md5=D1A5C491154EBAECAB635096FF16FE9 C.

Spinks, Bryan D. 2013. Do This in Remembrance of Me: The Eucharist from the Early Church to the Present Day. SCM Studies in Worship and Liturgy. London: SCM Press.

Susanti, Rina Dewi. 2017. "Tradisi Kenduri Dalam Masyarakat Jawa Pada Perayaan Hari Raya Galungan di Desa Purwosari Kecamatan Tegaldlimo Kabupaten Banyuwangi (Kajian Teologi Hindu)." Institut HIndu Dharma Nusantara, 2, 1.

Waluyo, Muhamad Edy. n.d. "NILAI-NILAI DAN MAKNA SIMBOLIK TRADISI NGANGGUNG," 15. 